\title{
Implementing Process Improvement Initiative: The Role of Visualisation and Standardisation Methods
}

Mumin A. Abubakre (E-mail: mumin.abubakre@ntu.ac.uk)

Nottingham Business School, Nottingham Trent University, Nottingham, NG1 4FQ, UK.

Amjad Fayoumi (E-mail: a.fayoumi@lancaster.ac.uk), Tel: +44 (0)1524 594725

Management Science, Lancaster University Management School, Lancaster, LA1 4YX, UK

Ismail Eleburuike (E-mail: ismail.eleburuike@gtt.net)

Regional Project Manager, GTT Inc, Sveavagen 163, Stockholm, Sweden

\begin{abstract}
Purpose: Due to the difficulties organisations face in implementing process improvement initiatives (PIIs), this research explores how visualisation and standardisation of business processes help organisations achieve PIIs to improve organisational performance.

Design and methodology: A multi-staged case study strategy that analyse qualitative data and performs a process modelling analysis of quantitative data.

Findings: The paper makes two main contributions to existing knowledge. Firstly, it explains how taking the visualised and standardised methods on a PIIs can reduce service delivery times and enhance organisational performance. Secondly, it demonstrates how adopting these dual methods offers a better chance of increasing organisational performance than using only a single method.

Research limitations: Although the paper considers the flexibility in the standardisation of business processes as it gives scope for innovation and creativity on the part of the process, it did not consider if flexibility is possible without breaking the standardised working way. Hence, future research can consider this. Also, future research can hypothesise the BPM model and test for statistical generalisability.
\end{abstract}

Originality: The research offers new insight into how and when both visualisation and standardisation of PIIs can benefit organisations.

Keywords: Business Process Management, Process Improvement Initiative, Business Process Model, Visualisation, Standardisation, Organisational Performance 


\section{Introduction}

Business process management (BPM) is a concept concern with end-to-end intra and interenterprise activities. BPM is closely related to several improvement-oriented methods, frameworks, and best practices that can be implemented and monitored to improve organisational performance (e.g., Dijkman et al., 2016; Marcinkowski and Gawin, 2019; Nadarajah and Kadir, 2016). Achieving the maximum improvements in business process performance in an organisation will require business process management (BPM) to promote growth and development (Dijkman et al., 2016; Van Looy et al., 2017). However, many organisations struggle to improve their processes due to the inadequacy of tools and use cases demonstrating how process performance can be enhanced (Marcinkowski and Gawin, 2019; Veit et al. 2014). Process improvement initiatives (PIIs) must explain the needs and goals of conducting process change and management. Typically, PIIs are not straightforward because organisations comprise interlinked and interdependent relationships between different BP activities. Therefore, various stakeholders may have different worldviews and interpretations of how they implement processes, and these multiple interpretations of existing processes and activities may be inconsistent with organisational policies. Therefore, to achieve process improvement, the different interlinked BPs should be visualised, aligned and standardised for all stakeholders' benefit to ensure commonality in the interpretation and understanding of how BPs enhance organisational performance.

Both process visualisation (Bobrik et al., 2007; Kolb and Reichert, 2013) and standardisation (Münstermann et al., 2010; Rondini et al., 2018; Villalba-Diez, and Ordieres-Meré, 2015) play crucial roles in the BPM main stages, particularly, design, modelling, and optimization stages and in the connections between them. Business process visualisation has proved its usefulness in facilitating communication (Vergadis et al., 2008), strategic thinking (Fayoumi and Loucopoulos, 2016; Graves, 2014) and decision-making (Stentoft Arlbjørn, 2011), as well as for analysis and design (Bobrik et al., 2007; Rinderle et al., 2006). Visual models can thus offer insights that are not otherwise attainable. Equally, standardisation is essential for ensuring intra- and inter-company interoperability. It provides a more natural and holistic way to learn its syntax and improve all stakeholders' understanding through its semantics (vom Brocke and Rosemann, 2015). The studies mentioned above have examined the implications of organisations adopting the visualisation and standardisation $(V \& S)$ methods in isolation. However, they have not explored the consequences if 
both methods were simultaneously selected. Understanding these implications is crucial to determine the precise role of each of the V\&S methods. Significantly, how each contributes to PIIs, and when organisations can benefit most from V\&S. Therefore, this paper focuses on PIIs (e.g., Lok et al., 2005; Nadarajah et al., 2016) to explore how the V\&S methods can improve BPs and organisational performance. Hence, the central research question is: How and when can the V\&S methods lead to successful process improvement and better organisational performance? Answers to this research question will contribute to the BPM literature and have implications for research and practice by showing how V\&S methods significantly enhance organisational performance through PIIs.

This paper reports on a longitudinal case study undertaken in four stages to show how an organisation can improve its communication and, subsequently, its processes and performance through the V\&S methods. The paper makes three main contributions to knowledge. Firstly, it explains how organisations can develop and implement a business process model based on V\&S methods. We present an assessment of the impact these methods had on the overall PIIs. The evaluation shows that V\&S methods in PIIs led to reduced service delivery times and enhanced organisational performance. Secondly, the study examined what an organisation would achieve if one of these methods is used in isolation, compared to if both ways were used to determine when to use either of these methods. Finally, it presents a discussion of the concept of process improvement and concrete representation depicted by our model, which shows the stages of when and how organisations can benefit most from V\&S. This leads to the conclusion that, when high efficiency is achieved, standardisation may no longer be required, mainly enabling rapid decisionmaking and innovative thinking. This may be because standardisation limits the way we think about new problems and constraints new ideas within the boundaries of standard routines.

The remainder of the paper is organised as follows. First, we review BPM and BP modelling research with specific reference to the V\&S methods in PIIs. Subsequently, we discuss our research methods and data collections and analysis strategy. This is followed by the case study representing our implementation of PIIs using both V\&S methods and presents our performance measures and evaluation. Then, we discuss our findings in evaluating the practical usefulness of V\&S methods and illustrating a general model that offers the experience gained from the case study. We conclude the paper by highlighting the findings, limitations, and future work. 


\section{Literature Review}

In the literature review, we elaborate on the research background and highlight visualisation and standardisation (V\&S) methods' importance during the Process Improvement Initiatives. In the following sections, we present a narrative literature review: To search for academic articles, 'OneSearch' and Google Scholar engines for academic literature were used. We used the following keywords: Business Process Management, Business Process Modelling, Process Improvement Initiatives. During the first stage, we collected 126 papers and filtered out based on three criteria. Papers were eliminated if they lack empirical or theoretical underpinning, are short conference papers and are technical-oriented.

\subsection{Business Process Management}

Business Process Management (BPM) identifies and documents the business processes throughout an organisation, which involve people, processes and technology, to measure and monitor process performance to achieve continuous process improvement and innovation (Klun and Trkman, 2018; vom Brocke and Rosemann, 2015; Wong, 2013). BPM entails that process owners continuously drive and manage business processes (BPs) so that all human resources perform their predefined activities accordingly to achieve organisational goals and objectives. Both researchers and practitioners see BPM as an embodiment of practice management's principles and a system that allows many organisations to survive in a competitive environment (Dijkman et al. 2016; Nadarajah et al., 2016). The primary focus for many organisations is to create value for customers, which can be achieved through the continuous monitoring of BPs (Alles et al., 2006; Leontjeva et al. 2016 ). Although BPM is vital for optimising organisational performance, many organisations still struggle to achieve this goal (Ariyachandra and Frolick, 2008; Marcinkowski and Gawin, 2019; Veit et al. 2014). There are various reasons for the difficulties in attaining organisational performance. For example, there are unclear definitions of BPM's goals and objectives or lacking

or inadequate management support for the processes to be implemented. Researchers and consultants have suggested various BP modelling tools and frameworks increase demand from many organisations to use BPM to attain operational efficiencies and improved performance. BPM entails several phases, including analysis, design and modelling, monitoring, and improvement. Vom Brocke and Rosemann (2015) described an improvement initiative as a focal aspect of BPM effort. The next section discusses the modelling effort, which plays a crucial role in improving processes. 


\subsection{Business Process Modelling}

Business Process (BP) modelling is a tool used for the analysis, evaluation, and improvement of BPs by systematically and comprehensively reviewing existing and alternative sequences of BPs (Damij, 2007; Figl, 2017). BP visually represents the flow of and the understanding of an organisation's business activities and the transformation of its inputs to outputs (Figl, 2017). Similarly, Eikebrokk et al. (2011) state that BP modelling helps visualise how an organisation conducts its business operations by defining its BPs, including entities, activities, constraints, decisions, and enablers, as well as their interrelationship. BP modelling provides an opportunity to represent an organisation's BPs to allow continuous improvement. BP modelling also includes the diagrammatic representation of BPs as an effective communication platform and enables identifying areas/aspects of organisational activities that require improvement. Despite the benefits of BP modelling, such as operational efficiencies and enhanced organisational performance, many organisations have not fully adopted BP modeling. The causes of this lack of acceptance are still unclear (Figl, 2017). Therefore, to promote the BPM approach, there is a requirement that a BP model should improve BPs and gain stakeholders' acceptance to enhance overall organisational performance.

\subsection{Process Improvement Initiatives}

As a process-improvement way of thinking and working, process improvement initiatives (PIIs) help organisations tackle limitations identified in their processes to enhance their performance (Dijkman et al., 2016; Van Looy et al., 2017). In organisations with a strong PIIs focus, work activities and tasks are consistently geared to making operating routines changes to achieve higher process maturity (Nadarajah et al., 2016). PIIs should have a broad focus on improving critical business processes so that customers' needs and requirements can be met rather than focusing on functional goals (Dijkman et al., 2016; Skrinjar and Trkman, 2013). As argued by Anand et al. (2009), two broad areas of action are required for sustained improvement - the execution and the coordination of process improvement projects. The literature on PIIs emphasises that inadequate coordination of processes undermines the practical realisation of objectives (Anand et al., 2009; Dijkman et al., 2016). These studies explain that organisations can perform better if they simplify, 
re-engineer, integrate, and align their different processes in the quest to increase productivity and the benefits of adopting the standardised approach to PIIs.

Further, the literature suggests that process improvement in organisations requires a universal scientific method or a standard set of steps (e.g., Rondini et al., 2018; Villalba-Diez, and OrdieresMeré, 2015). Villalba-Diez, and Ordieres-Meré (2015) argue that a standardised approach for process improvement can give rise to a common understanding of the basis on which to connect processes within an organisational network. This is essential because a standardised process ensures that the knowledge created during a PIIs is understood by all stakeholders and is not restricted to a particular individual or project team. It also helps in resource allocation, performance measurement, policy enforcement, and benchmarking. At the same time, however, it is also vital to simplify communication and overcome different perceptions to attain more efficient and effective communication between processes to align interprocess communication in one single standard (Kolb and Reichert, 2013; Vergadis et al., 2008; Villalba-Diez, and Ordieres-Meré, 2015). This is why the visualisation method is a second requirement for process improvement. Perhaps if the BP model processes are communicated (i.e., visualised) to stakeholders in a standardised manner, stakeholder will accept the model's implementation. The next section proposes a conceptual framework for developing and implementing a PIIs.

\subsection{Literature Critique and Research Focus}

The business environment is dynamic, and Business Process Management (BPM) specialists should continuously update, measure performance, and improve business processes (BPs) to keep them relevant (Nadarajah and Kadir, 2016). We argue that any discussion of the PIIs concept to enhance organisational performance requires understanding two requirements: visualisation and standardisation $(V \& S)$. For the standardisation requirement, it is necessary to know how and why organisations can perform better if they standardise business functions and activities, i.e., integrate and align their different processes. Research in supply-chain management (e.g., Villalba-Diez, and Ordieres-Meré, 2015; Phelps, 2006) suggests that the standardisation of BPs facilitates the attainment of goals such as improving operational performance, reducing costs, and improving communication. Münstermann et al. (2010) claim that process standardisation is considered a necessary precondition for process performance. They argue that the standardisation of BPs has a 
substantial positive impact on business performance, especially in reducing costs and improving the quality of BPs the time required. In another study, Sánchez-Rodríguez et al. (2006) found that the standardisation of processes for sourcing and purchasing materials has a very significant positive effect on business performance, helping many organisations to stay within a budget for materials, improve the quality of materials, delivery times from suppliers and inventory performance. In more recent studies, Rondini et al. (2018) and vom Brocke and Rosemann (2015) echo the above conclusions on the importance of standardising BPs to workflow management and enterprise systems, again citing improvements in time, costs, and quality.

However, it is challenging to achieve efficiencies through the standardisation of BPs due to integrating different practices that involve people from other divisions, subject to various rules and policies, and draw on different skill sets (Romero et al., 2015). Earlier studies also emphasised the importance of the social aspects of the business process (i.e., socio-technical perspective) which are embedded in BPs as a challenging aspect of integrating and optimising socio-technical systems in organisation (e.g., Melao and Pidd, 2001; Tang et al., 2013; vom Brocke et al., 2016). The sociotechnical perspective on BPs focuses on complex human interactions and relationships and their effects on work systems. Thus, through V\&S, sharing common understanding among relevant stakeholders is crucial for BPs, while streamlining human-technology interactions should increase efficiency. The structured and formalised approach to BPs, which is represented by standardisation is also vital. Wüllenweber et al. (2008) proposed a definition of a measurement construct for 'process standardisation', they argue that process standardisation ensures that process activities are transparent and uniform across the value chain. Therefore, this 'process standardisation' construct is the first step in developing and implementing a BPM in practice. It is necessary to explain how organisations could consistently integrate and align various BPs, i.e., implement standardisation, and explain how BPs can be simplified and communicated to all stakeholders, i.e., through visualisation. This is the second requirement, and guidelines should be provided on how and why the visualisation approach to BPs can be useful in developing a BP model. The literature explains how and why adopting a visual representation of problem-solving can enhance the way managers perform their tasks (e.g., Figl, 2017; Stentoft Arlbjørn, 2011). Visual representation helps managers to simplify ideas and to communicate complex ideas to different stakeholders. Visual representation allows organisations to perform cognitive and operational functions (Fayoumi and 
Loucopoulos, 2016; Graves, 2014). Visualisation allows cognitive functions such as looking at problems in new ways and operational processes, i.e., monitoring and developing a better understanding of the interrelated and complex business activities' flow to improve organisational performance. These visualisation functions are vital because BPs involve different people, generating considerable ambiguity and impacting organisational performance (Marcinkowski and Gawin, 2019; Nadarajah and Kadir, 2016). Figl (2017) echoes this point, suggesting that the visualisation of BPs offers a chance to improve the BP by providing different options to people on how they can fulfil their roles and responsibilities.

Similarly, Vergadis et al. (2008) argue that organisations do not have explicit knowledge about complete process flows. Therefore, BP visualisation would lead to a better understanding and management of the knowledge involved in BPs. Consequently, organisations that seek effective performance management and want to monitor their BPs require proper visualisation of their daily operations (Fayoumi and Loucopoulos, 2016; Rinderle et al., 2006). Applying the visualisation method to BPs should help develop a BP model, ensuring that organisational goals are achieved efficiently and effectively (Stentoft Arlbjørn, 2011). That way, it allows practitioners to understand how to perform a thorough analysis of BPs in an organisation. This study focuses on visualisation as a primary underlying method for developing and implementing a BP model in practice to improve organisational performance. The $\mathrm{V} \& \mathrm{~S}$ methods complement each other, highlighting their role in enhancing business performance. The standardisation method constitutes a basis for understanding how to integrate and align different aspects of BPs consistently. However, it does not give clear guidance on how the complex interrelationship of BPs can be identified, monitored, and facilitated. The visualisation method provides a means and complements the standardisation method. The importance of the V\&S methods is illustrated by the work Vergadis et al. (2008), which surveyed respondents regarding their current BP practices. Their results showed that most of the respondents indicated that they preferred dealing with BPs in a structured manner to gain a clear and concise view of organisation's BPs and a solid understanding of their flow. Therefore, the standardisation method works with the visualisation method as a rational way of managing BPs, allowing different stakeholders to see the value of aligning their various processes to realise the shared objective of enhanced organisational performance. 


\section{A Research Approach to Develop, Implement and Validate a Business Process Model in Practice}

\subsection{Research Method}

We adopted a case study approach (see Yin, 2009) because it helps provide a rich description of the phenomena investigated (Siggelkow, 2007). The organisation selected for the case study is a leading international company keen to implement change in its business processes and was willing to collaborate in the research. This research mainly focuses on customer requests and the ICT service delivery process.

\subsection{Case Study Description}

The host organisation is referred to as GFBE is a service delivery division of a leading global telecommunications company. GFBE provides ICT services globally for the research and development part of the global ICT Company. It aims to create an environment of shared values, trust, and collaboration, in which all the stakeholders work together to ensure the IT/telecom company be the global market leader. We researched three subunits of GFBE: Cloud, Evolved Infrastructure (EI) and, Mobile Core (MC).

\subsection{Research Design and Data Collection Methods}

The research used a mixed-methods approach, which included qualitative interviews, quantitative data generated from work systems, unobtrusive observations, and document analysis (project documentation, e-mails, internal memos, and the company website). This practical research philosophy allowed various forms of data to be collected (qualitative and quantitative) by focusing on the research problem and using pluralistic approaches to gain in-depth knowledge (Patton, 1990). It also provided a basis for describing how GFBE manages its business processes (BP) in a representative and consistent way. In other words, the mixed methods approach made it possible to triangulate data and achieve construct validity and enhance the richness of the results (Yin, 2009). As suggested by Weber (2004), care was taken to avoid preconceptions when understanding how business process management (BPM) can improve organisational performance from the two visualisation methods and standardisation methods. 
We conducted a longitudinal study as it involved multiple periods (Barley, 1990; Mustonen-Ollila and Lyytinen, 2003; Pettigrew, 1990). Most of the data was gathered over eight months between October 2014 and March 2015. The fieldwork commenced with some informal face-to-face interviews with managers to gain an initial understanding of their ways of working and the current state of relevant processes. The interviewees were ICT Engineers, an ICT Project Manager, an ICT Line Manager, ICT Hardware Coordinators, ICT Local Operation Managers, and ICT Asset Manager. The interviews revealed ambiguity and a lack of standardisation in the existing business and IT processes. In addition to the interviews, staff members were discreetly observed in their ICT service delivery activities to get a real-life picture of everyday business processes in GFBE. Quantitative data was gathered using the Key Performance Indicator (KPI) - Lead-Time Loss (LTL) to measure the procurement customer tickets within three units of GFBE, namely Cloud, Evolved Infrastructure, and Mobile Core. See Table I.

\section{Table I: Functional Groups of GFBE Informants}

\begin{tabular}{|c|c|}
\hline Functional Group & Number of Informants \\
\hline Cloud & 3 \\
\hline Evolved Infrastructure & 4 \\
\hline Mobile Core & 4 \\
\hline Total & 11 \\
\hline
\end{tabular}

GFBE's Request Tracker Tool (RTT) was used to understand existing BPM in GFBE. This tool tracks customers' requests and records when the Service Delivery Department fulfils the requests, and it was used to capture data on lead-times for the procurement of customer tickets. This data was then analysed to give a picture of GFBE's BPs before applying the V\&S methods. The ICT services provided include the procurement of ICT products, ICT product configuration and installation, asset management, and support for ICT services. The RTT tool was also used to analyse how business process modelling improves the BPM of an organisation. 
Subsequently, ten formal semi-structured interviews were conducted with ICT managers. These provided an opportunity to seek clarification of some of the quantitative data which was gathered. Interviews were also used to evaluate the results of adopting V\&S methods for BPM. The interviews lasted between 35 and 55 minutes. Although the interviews were not tape-recorded, notes were taken and expanded into field notes immediately upon completing the interviews. Finally, as Walsham (2006) recommended, we observed that GFBE developed and implemented a BP model and determined the impact of the applied model on organisational performance. As this was a longitudinal study, it was possible to observe the different processes involved in the BP model, which was implemented over a period, which allowed the empirical work to be validated. We summarise the research design in Figure 1.

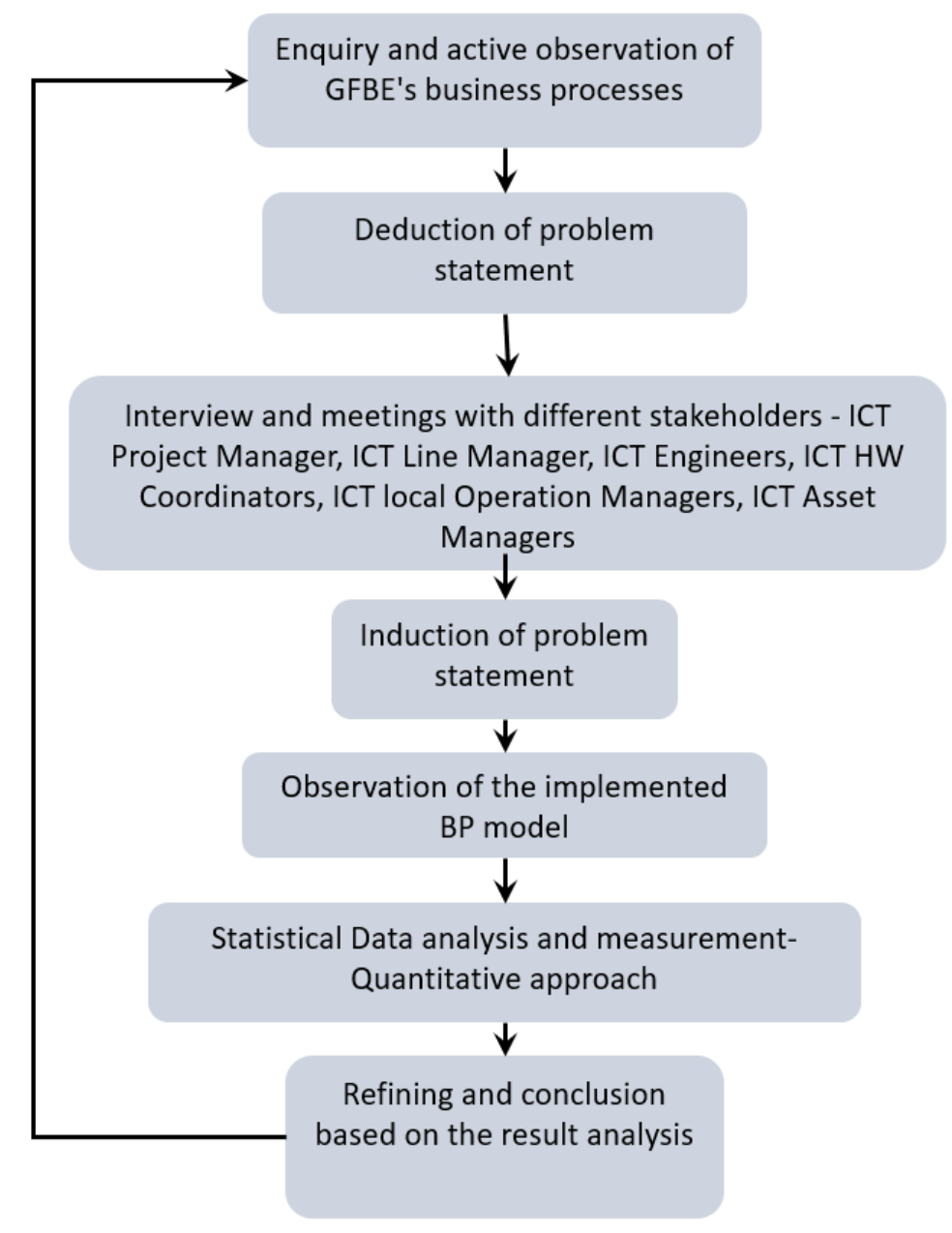

Figure 1: Research Design and Process 


\subsection{Analytical Strategy}

The majority of the data for this study is quantitative. It was analysed using the Business Intelligence (BI) tool Minitab 17 Statistical software and Microsoft Excel, and deductions were drawn from the analysis. From the initial analysis, a conceptual standardised process model was developed using a business process (BP) modelling tool, in the form of flowcharts which provided a visual representation of the BPs, while the empirical work was undertaken. The process model which was developed was implemented in GFBE to assess its usefulness and suitability. Subsequently, another set of data - GFBE's service delivery requests - was captured using the RTT. This data was analysed to illustrate the reduction of the order-to-cash (i.e., lead-time lost), to determine whether the process improvement initiative had enhanced organisational performance.

\section{The GFBE Case Study}

The eight-month case-study research consisted of four phases (see Figure 2). The first phase involved analysing GFBE's business processes (BPs) and took place in October 2014. The second phase occurred when GFBE developed and implemented a BP model designed to improve its BPs. The phase lasted from November 2014 to mid-January 2015. From mid-January 2015 to February 2015, the third phase evaluated the BP model's impact on GFBE's productivity. The fourth and final phase (May to June 2015) was when GFBE decided to abandon the standardisation method for part of their existing business model for further optimisation. 


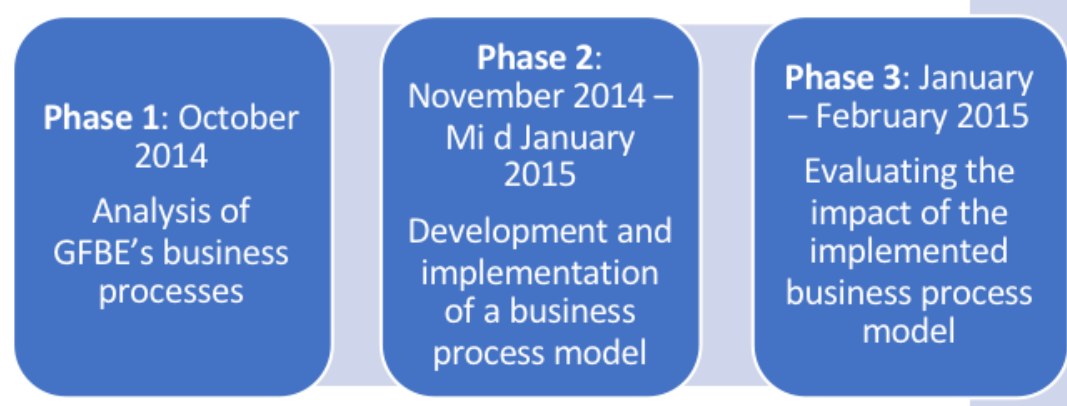

Phase 4: May -

June 2015

Optimise and

innovate by

breaking part of

the standard

business process

\section{Figure 2: Phases of the Research}

\subsection{Research Phase 1: Analysis of Business Processes before Adopting the Standardised and Visualised Approaches}

There were two KPI measurements (i.e., lead-time loss and lost lead-reduction) at GFBE for measuring service delivery to customers. Figure 3 shows the KPI measurement skeleton indicating how measurements were calculated using the RT tool. The parameters used to derive 'Lead-Time Loss' (LTL) and 'Lead-Time Reduction' (LTR) are 'Ticket Created Date', 'Agreed Due Date' and 'Ticket Resolved Date', as shown in Figure 3. 


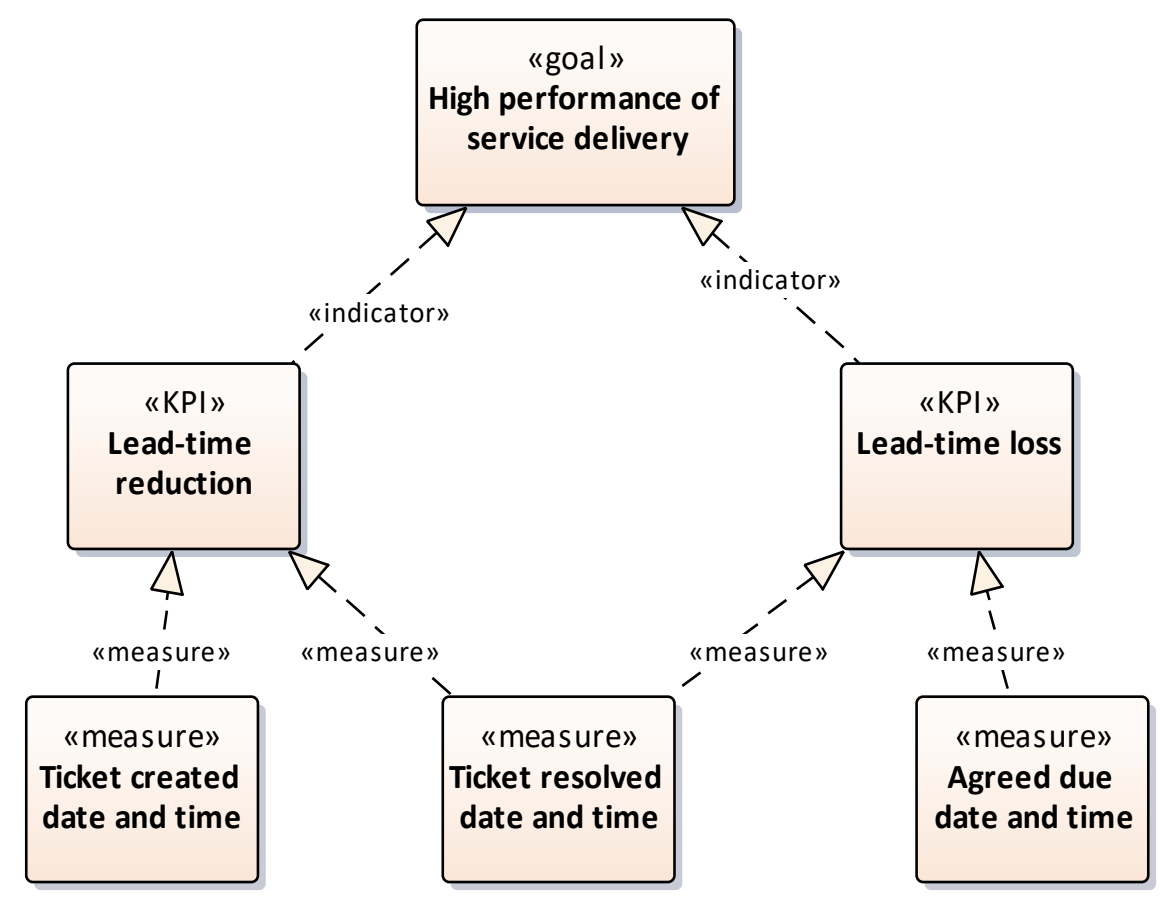

Figure 3: KPI Measurement Skeleton for GFBE ICT Service Delivery Organisation

LTL $=$ Ticket Resolved Date - Agreed Due Date, while LTR $=$ Ticket Resolved Date - Ticket Created Date. Based on the input from the LTL and LTR derived from Figure 3, LTL KPI value = $\Sigma \mathrm{LTL} / \Sigma$ (number of service requests (SRs) measured in days), and LTR KPI value $=\Sigma \mathrm{LT} / \Sigma$ (number of SRs measured in days). LTL is the time lost after the due date agreed with the customer. LTR is the total lead-time between the customer request and when the Service Delivery Department renders the service.

For this study, only the KPI - LTL measurement is considered for analysis to help analyse the order-to-cash cycle (i.e., the lead-time for fulfilling customer requests agreed by the parties involved). The initiative undertaken by GFBE was to reduce the order-to-cash. The reduction of LTL is vital since it reduces the overall costs of fulfilling customer requests, thus increasing value for stakeholders and improving organisational performance. Nevertheless, the results will take the visualisation and standardisation (V\&S) methods to BP modelling to illustrate how reducing the order-to-cash cycle can enhance organisational performance. Figure 4 shows the non-uniform 
distribution of data for the KPI LTL of the three subunits of GFBE's ICT Delivery Department (Cloud, EI, and MC).

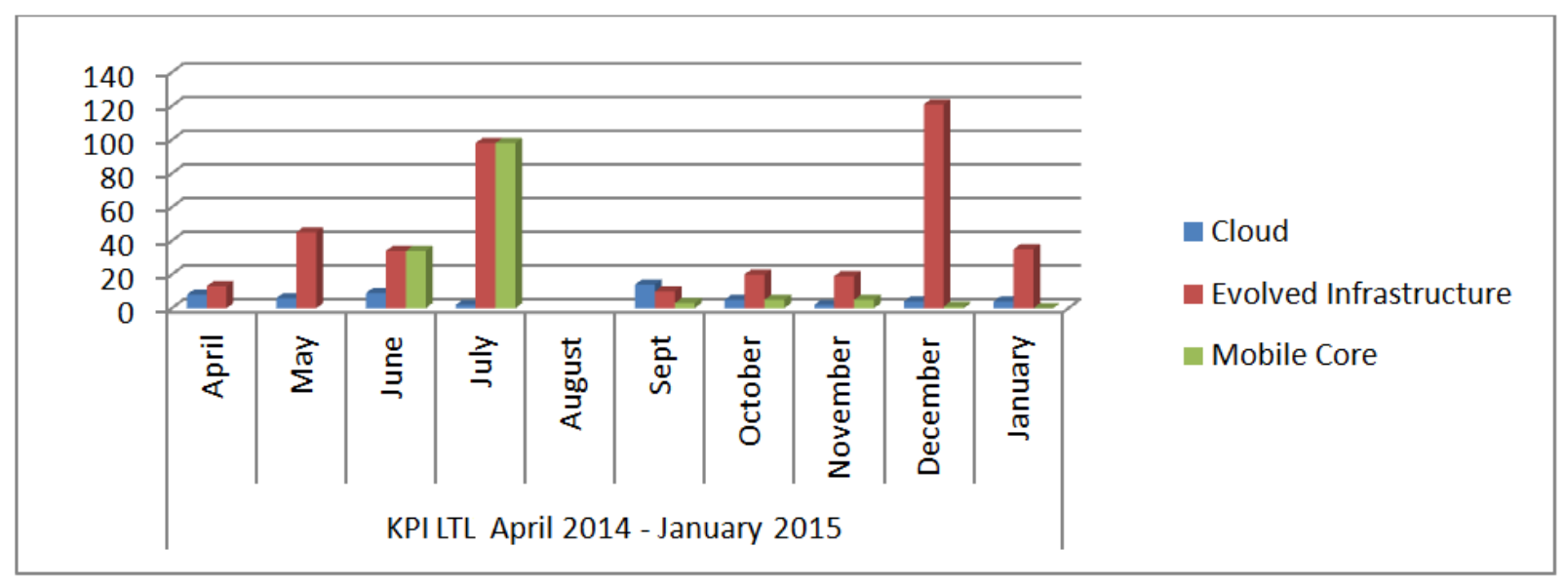

Figure 4: KPI LTL between April 2014 and January 2015 for Cloud, EI, and MC

The business process (BP) previously in use, did not have any concrete agreement when the service delivery organisation should deliver customers' requests. Communication between the service delivery organisation and the customer was ineffective. Customers did not adequately communicate to the service delivery department the date they wanted their requests to be met. Also, the service delivery department did not disclose to customers when they could meet their requests, thus failing to meet customers' needs by the time they requested. Customers expected their procurement requests to be delivered within two weeks, but these requests took eight weeks to deliver in reality. Echoing Vergadis et al.'s (2008) findings, the customers did not have explicit knowledge about the service delivery team's complete process flow in dealing with customers' requests. The different time expectations for service delivery caused long delays in responding to customers' requests and increased LTL. Figure 5 shows a snapshot from the RT tool, an example of the long delays in responding to customer requests. 


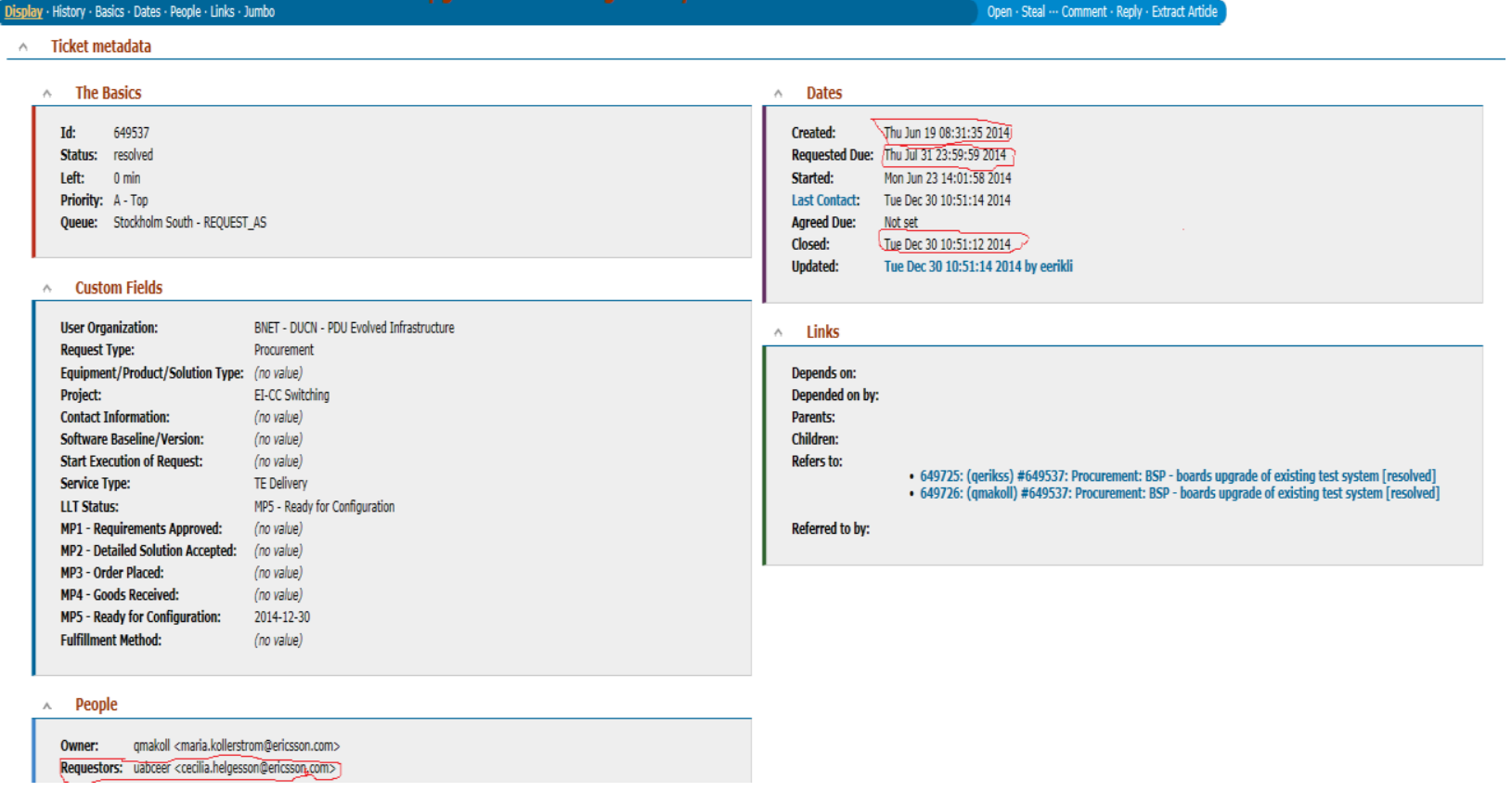

Figure 5: Snapshot of Customer Request

There was no clear structure for how GFBE should handle customer requests, thus causing LTL to increase service delivery. The lack of structure shows that there was no standardisation in the BP, as there was no agreed standard set of steps (Münstermann et al., 2010; Rondini et al., 2018; Villalba-Diez, and Ordieres-Meré, 2015) for the interaction between the service delivery team and customers. This prevented a shared understanding between the stakeholders of how processes are carried out (Villalba-Diez and Ordieres-Meré, 2015). As argued by Anttila and Jussila (2013), if there is no model to visualise the way BPs are carried out, there is a risk that the desired results will not be achieved. There was also no means by which customers could view the way the service delivery team was operating, and therefore no opportunity to correct and communicate expectations such as visualisation (Bobrik et al., 2007; Kolb and Reichert, 2013). The lack of V\& methods for the BPs in the departments studied reduced the process flow efficiency and hurt organisational performance. Figure 6 shows a snapshot from the RT tool, an example of the extended delay in responding to customers. 


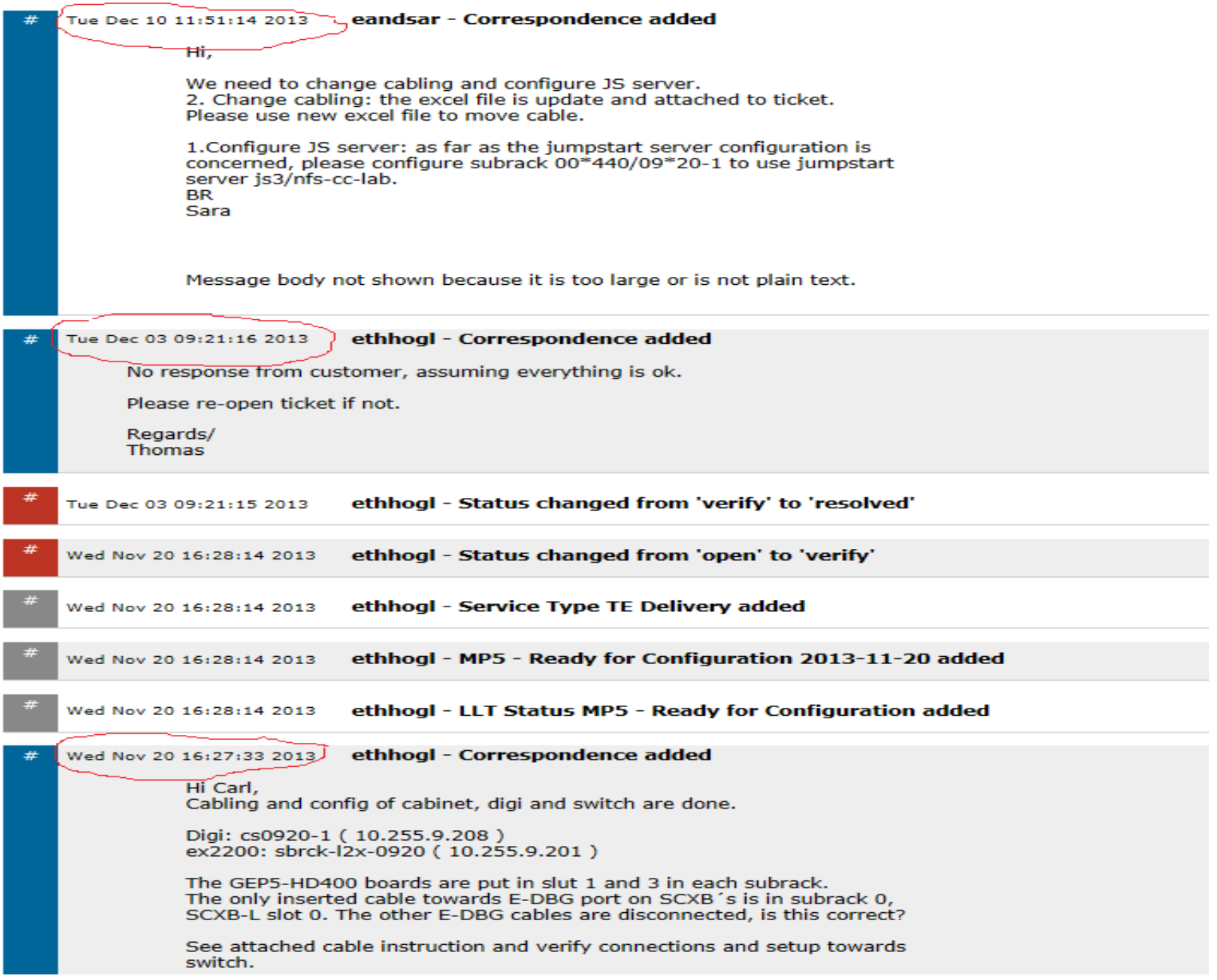

Figure 6: Snapshot of the Prolonged Delay in Response from the Customer due to Process Limitation

Figure 6 shows that on November 20, the service delivery team requested the customer to confirm their request's completion, but there was no response from the customer. After two weeks, i.e., on December 3, the support team decided to close the ticket. Subsequently, the customer reopened the ticket rather than opening a new ticket to request additional requests, which was not part of the initial request. This shows that the customer's request came with inadequate information. Information went back and forth between the customer and the support team, which negatively affected the service delivery performance measurement, i.e., the lead-time. In one of the interviews, an ICT Project Manager discussed this case:

The constant restructuring of the customer team (product development unit) and IT support made it difficult to handle information and processes efficiently. That was why the ticket's 
information was sent back and forth between the support team and the customer. The inefficiency in dealing with the processes was due to an undocumented standardised process being in place. ICT Project Manager

Informants further confirmed that the lack of V\&S of BPs was responsible for the irregularity in managing BPs:

We cannot see the full picture of what happens within the process flow when a customer requests a service; that is, there is no visualised way of working and dealing with requirements. The lack of visualisation makes it tough to understand what is required by the customer. (ICT Asset Manager)

The lack of V\&S of the BPs in GFBE was an obstacle to meeting the target set - reducing leadtime lost in service delivery and hurting the organisation's overall performance.

\subsection{Research Phase 2: Implementation of the Conceptual Business Process Model}

The second phase of the research involved analysing GFBE's business processes (BPs) upon implementing a BP model. We used the BP model standard to fulfil this task, see Figure 7. 


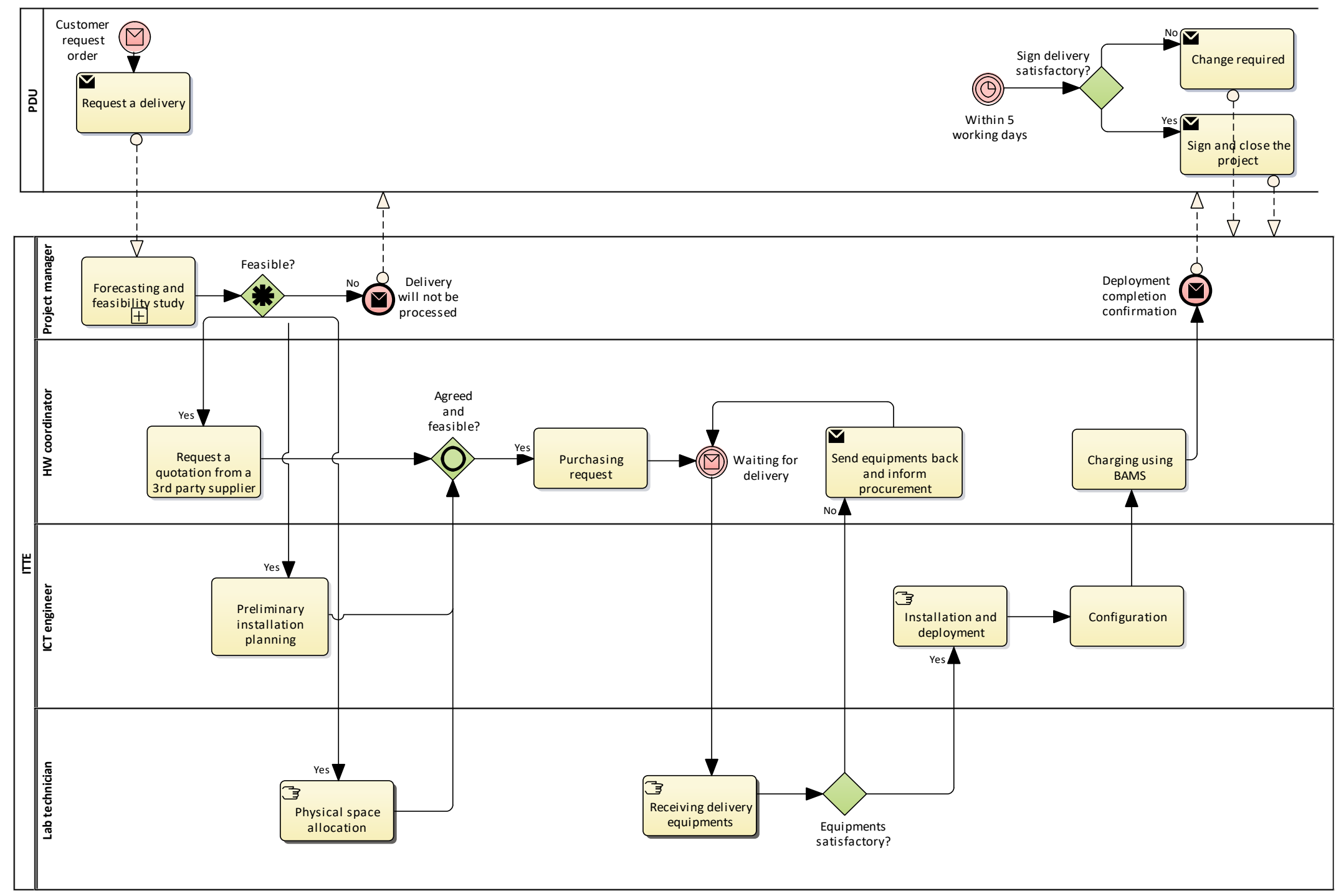

Figure 7: Business Process Model Adopted by GFBE 
GFBE implemented the BP model to achieve standardisation by integrating and combining the different interrelated aspects of their BPs, allowing the visualisation, understanding, and management of the flow of complex BPs. Figure 7 is the conceptual BP model that presents an overview of the delivery process (process mapping), showing in visual form the standard ways of carrying out daily activities, starting with customer's needs to the point when GFBE has completed delivery of the services.

The component units and activities of the model are as follows. The Product Development Unit (PDU) informs the Information Technology Test Environment (ITTE) that a customer has made a request. ITTE is the service delivery organisation and is responsible for acting on customer requests. The first step is that the project manager forecasts and does a feasibility study of the customer's request, i.e., request IT hardware. Subsequently, an investment request identification (IR ID) is generated, an input for the procurement activities. The service delivery organisation uses the booking asset management system (BAMS) to charge the customer according to the hourly rate for using the ICT infrastructure, which is the operational expenditure. The ICT Hardware Coordinator (HWC) is responsible for coordinating all stakeholders to ensure effective and efficient end-to-end service delivery. The Project Manager (PM) has overall responsibility for the project, including planning, budgeting, and end-to-end delivery of the service.

This high-level process model depicts a standardised procedure for dealing with customers' requests and shows all the activities from the customer's request through procurement, installation, and delivery. As shown in the model, the first step is for a customer to request the supply of particular hardware needed for their project. This is represented as PDU in Figure 7. The customer sends their request to GFBE, described as ITTE in Figure 7. The third step is for the supplier to provide a quotation investment feasibility review that happens simultaneously. The Investment ID is the input to the procurement of any product. Procurement is triggered in the fourth step, leading to the fifth step in which delivery is made to a data centre, and installation and configuration begin. The final stage is when monthly charging for the use of the test equipment starts.

The process model presented here visualises a standardised procedure that should be followed when dealing with customer requests and to help avoid the sort of problem previously illustrated, 
i.e., the high LTL which arose when dealing with a request. As shown in Figure 7, which is in line with the arguments of Wüllenweber et al. (2008), the V\&S of GFBE's processes enabled GFBE's activities to be uniform and transparent to all stakeholders.

Upon implementation of the BP model, control measures were put in place. The control measures ensured that the model captured all of GFBE's service delivery requests and their fulfilment time. The corrective action was taken to amend and align any output variations, i.e., impact lost leadtime. Following the procedure proposed by Ariyachandra and Frolick (2008), GFBE undertook corrective actions such as adding to, rearranging, or eliminating process activities to facilitate standardisation, elimination of activities which were duplicated or carried out by two people (e.g., having a process owner as well as an activity actor). The additional activities were to improve the smoothness of the process flow and to optimise the time and costs of activities until the new process design was completed and agreed. These corrective actions meant that GFBE improved communication and awareness of BPs and got customers involved in the process flow design. GFBE had meetings with its customers to get feedback. The obtained feedback led to further critical thinking to ensure that the implemented business process management (BPM) would enhance organisational performance.

The fallout of the meetings was that GFBE realised a need to add another process, i.e., 'installation planning stage 1' before the procurement process. Initially, it was unclear at the delivery process stage how and where to install the product. This resulted in having two processes - 'installation planning stage 1 ' and 'installation planning stage 2 '. Similarly, the 'lab space allocation' process was added as a simultaneous process before the 'procurement' process. The addition of these two processes improved the efficiency of the process flow.

During the model design and implementation, the 'Quotation' process was initially done before the 'IR ID' process. However, after implementing the V\&S methods, it became clear that the 'Quotation' process had to be done in parallel with the 'IR ID' process. So, GFBE rearranged the processes accordingly, as shown in Figure 7. Again, as illustrated in Figure 7, the 'Installation planning stage 1' process was initially seen as the first ITTE activity. However, it was then realised that these four separate processes had to be parallel with one another, so they were rearranged. 
Before the amendment of the model, a review process had occurred between the PDU delivery unit triggering a ticket and the start of ITTE processing activities. This review process determined if it was realistic for GFBE to deliver what PDU was asking for regarding GFBE's resources. The review produced back and forth communication, which was time-consuming and affected the delivery of the services. Therefore, both stakeholders agreed that they should eliminate the review process. Nonetheless, they controlled the absence of the 'review' process by having initial meetings with the relevant stakeholders before any ticket is triggered, which led to a reduction in lead-time.

The BPM model's design and implementation were carried out with the management team's support and the full support and involvement of users, including customers and service delivery organisations. This is consistent with previous studies highlighting the need for the human element and social context to be embedded in BPs to achieve an efficient system (e.g., Melao and Pidd, 2001; Tang et al., 2013; vom Brocke et al., 2016). The case presented here describes how a series of awareness-raising and promotional campaigns were conducted for all the stakeholders involved in the end-to-end flow of the service delivery processes in GFBE to show the importance of having a visualised and standardised BPM in place. This also illustrates the points made by Ariyachandra and Frolick (2008) and Wong (2013) about the crucial role played by top management and users represented in the BPM's development and implementation.

\subsection{Research Phase 3: Evaluating the Results: The Impact of the Business Process Model}

The revised business process (BP) Model adds value to GFBE by improving process flows and organisational performance. The RT tool was used to capture another set of data, i.e., daily customers and ICT service delivery-logging requests, to determine the impact of the revised model on performance. The data were analysed to show the reduction in the order-to-cash (KPI lost lead time), which resulted from shortening the ICT service delivery lost lead-time, which was one of the organisation's strategic initiatives for achieving improved organisational performance. The analysis compared the lost lead-time between the fourth quarter of 2014 and the first quarter of 2015 to demonstrate the impact the BP model upon incorporating visualisation and standardisation (V\&S) methods had on the organisation's performance. The analysis of the ICT service delivery 
tickets, i.e., customers' procurement request tickets, shows a reduction in the LTL of BP. For example, BP, such as procurement, has a domino effect by reducing the time lost in all other related BPs such as installation, configuration, and ICT support. Figure 8 shows the lead-time (in days) for procurement customer service requests for the fourth quarter of 2014 and the first quarter of 2015, i.e., before and after the BP mapping was modelled and put into practice.

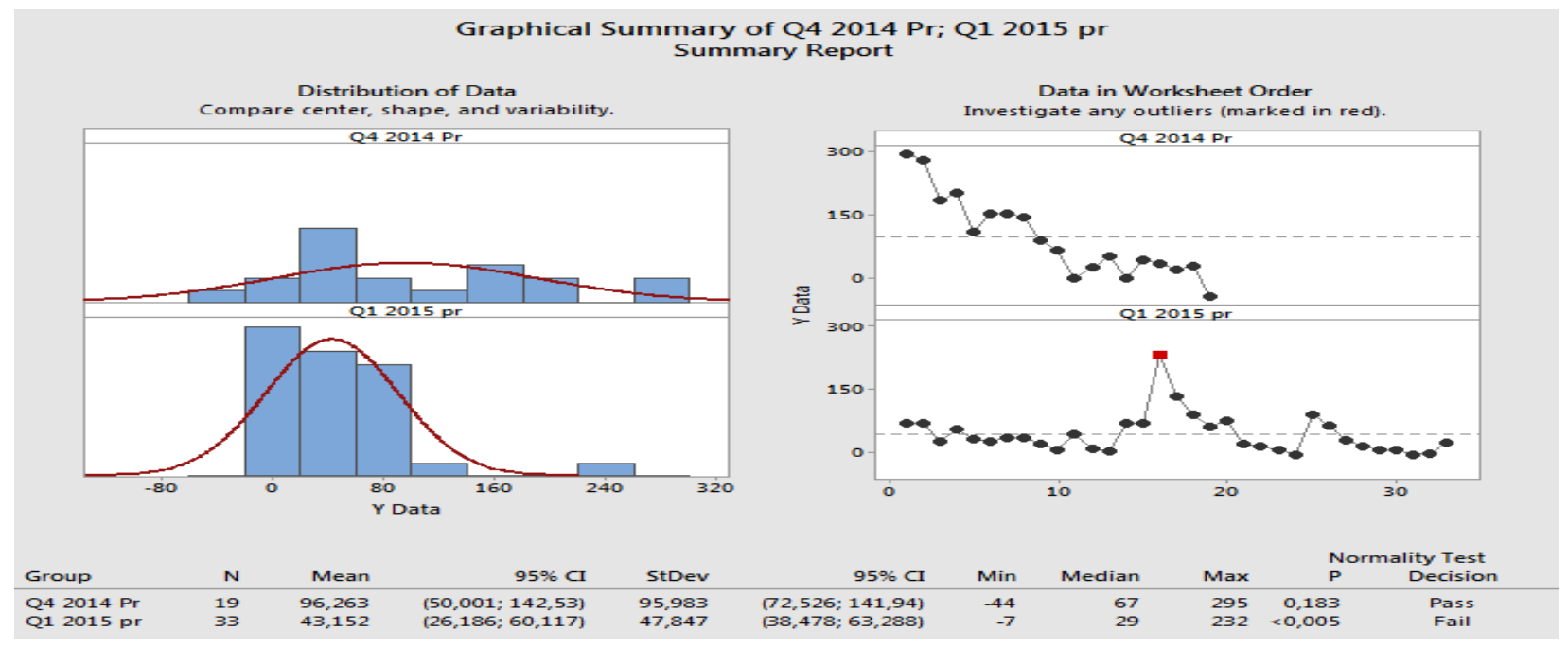

Figure 8: Simulation of Lead-Time (in Days) for Procurement Customer Tickets, Q4 2014 and Q1 2015

As shown in the graph above, the lead-time data distribution (measured in days) of the customer service request tickets in the fourth quarter of 2014 is unusual. Similarly, the spread of lead-time data on the right-hand side of the graph for the same quarter also shows an irregularity in how GFBE's carried out their BPs. On the other hand, in the first quarter of 2015, when the BP model was put into practice, it can be seen that the lead-time data has a normal distribution. This normal distribution indicates that a visualised and standardised way of dealing with GFBE's BPs is in place. This is clearer on the right-hand side of Figure 8. Lead times are spread uniformly, with only one outlier lead time of 200 days due to an exceptional case involving the procurement of trial ICT hardware, which usually takes longer. 
As shown in Figure 8, the V\&S of GFBE's BPs allows the rapid identification of issues that require solutions, consequently improving organisational performance (Ariyachandra and Frolick, 2008; Marcinkowski and Gawin, 2019; Veit et al. 2014). The results also show that the lost lead-time for customer procurement service requests reduced in the first quarter of 2015 when the visualised and standardised BPM methodologies were applied compared to the fourth quarter of 2014 when there were no visualised and standardised BPM methods in place. Consistent with the literature, standardisation helped because the approach enabled GFBE to make improvements in product procurement, the planning of product expenditure, and the time taken for delivery from suppliers to customers, as well as to improve workflow management overall (e.g., Sánchez-Rodríguez et al. 2006; vom Brocke and Rosemann, 2015). Simultaneously, visualisation helped GFBE stakeholders monitor and better understand the interrelated and complex flows of their business activities, i.e., to undertake cognitive and operational functions (Fayoumi and Loucopoulos, 2016; Graves, 2014). These visualisation functions were vital for reducing the LTL by resolving customers' and the service delivery team's different time expectations to customers' requests.

Figure 9 shows the reduction of LTL for procurement customer service requests in the first quarter of 2015 compared to the fourth quarter of 2014.

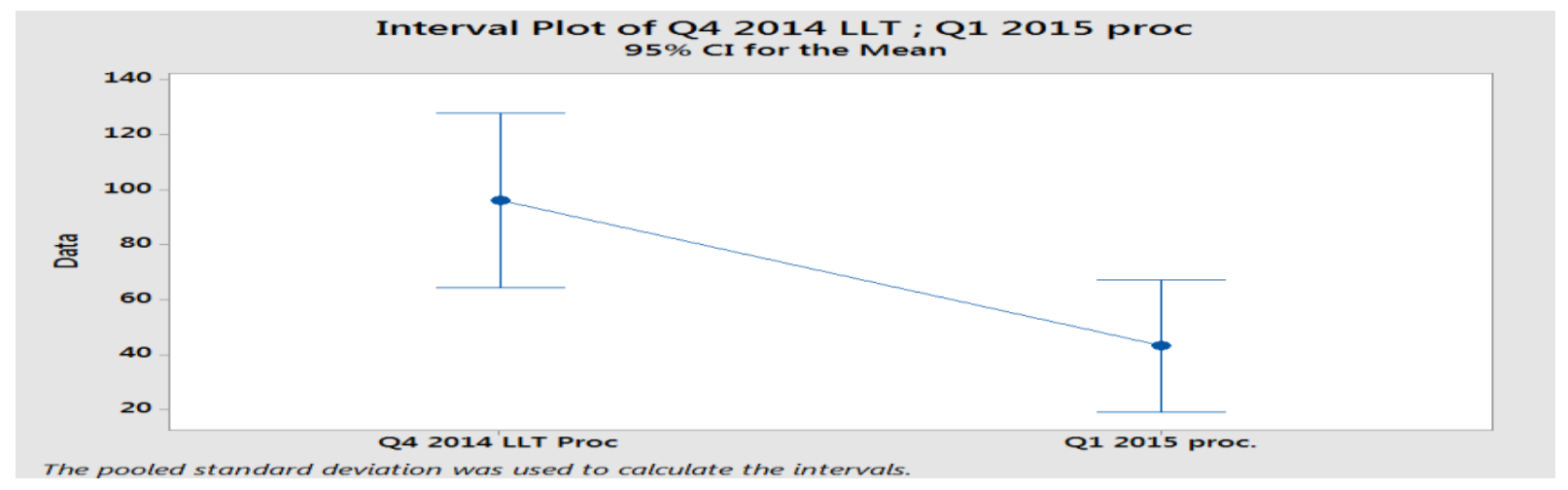

\section{Figure 9: Lost Lead-Time (in Days) for Q4 2014 Simulated against Q1 2015}

As shown in Figure 9, the mean value (LTL) of customer procurement service requests fell from 96 to 43 days, and this happened as a result of the visualised and standardised BPM methods implemented in 2015. This reduction in the LTL shows that GFBE's top management team had fulfilled the aim of one of its strategic initiatives, i.e., a decrease in order-to-cash. Furthermore, we 
performed a 2-Sample t-Test for the mean of the first quarter of 2015 and the fourth quarter of 2014 LTL. As indicated in Figure 10, the result shows that the LLT for customer procurement tickets in the first quarter of 2015 was less than in the fourth quarter of 2014, with a confidence level of 95 percent (that is, a 0.05 level of significance).

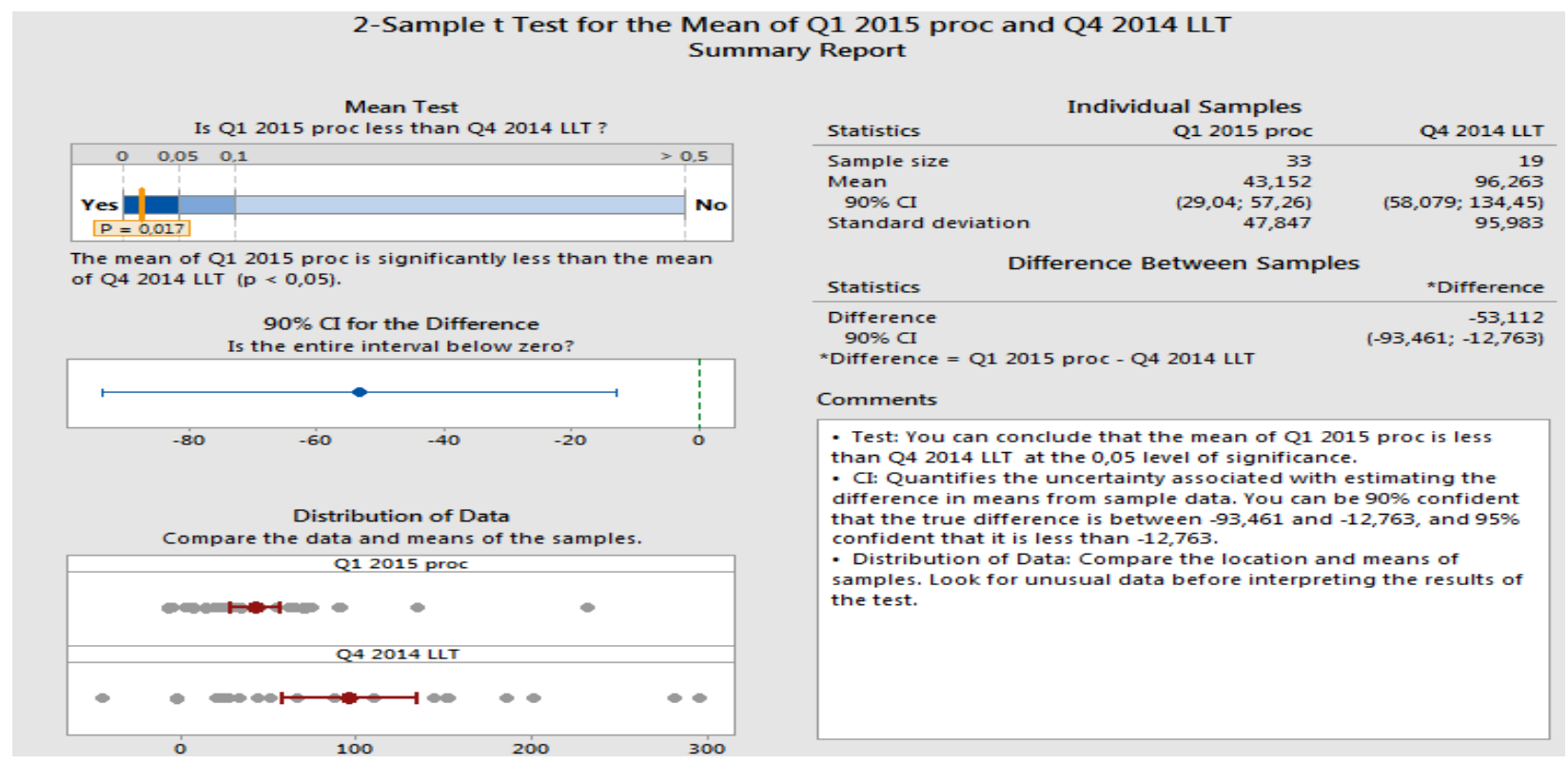

Figure 10: 2-Sample t-Test for the Mean of Q1 2015 and Q4 2014 LLT for Customer Procurement Tickets

In summary, the analysis of the results further corroborates the claim that the implemented BP model improved GFBE's BPs and organisational performance regarding cost reduction, user satisfaction, and time savings, which was the primary focus of this research.

\subsection{Research Phase 4: Breakdown of the Standardised Process to Enable Further Improvement and Innovation}

GFBE realised that to enable their staff to work effectively and innovatively, they needed to break down some of the regular activities further. Although the measures taken resulted in significant performance improvement, GFBE noticed room for further development if two of the activities 
were made less standardised. The activities for 'purchasing request' and 'receiving the delivery' could be made more flexible to enable hardware coordinators and lab technicians to source devices differently. For example, they could purchase in phases to allow more time for testing and performance measurements, buy from multiple third parties and, customise the infrastructure locally. They could avoid waiting by assigning responsibility to someone from the department to buy the equipment in person from approved third parties. That way, they could change part of the purchasing process without going through the whole procurement process and document everything in the procurement system later. The change enabled staff to promptly react to changes and make quicker contextual decisions, for example, by rapidly evaluating the purchasing and delivery methods and selecting the most suitable one, such as 'click and collect' feature offered on e-commerce systems. After this change, the analysis of the data (second quarter of 2015) showed an improvement in both purchasing and delivery times and, therefore, less time spent on the process overall.

This outcome indicates that the process's continuous improvement is crucial, drawing on stakeholders' experience and knowledge to respond rapidly to change cues and the evolving circumstances of daily business activities. It is also essential to note that the process's visualisation helped GFBE identify what parts of the process need change and how to reflect the change in the new process and rules models' documentation.

\section{Discussion}

The design and implementation of the business process (BP) model show how the visualisation and standardised (V\&S) methods can increase the efficiency and effectiveness of the BPs. The developed BP model was tested in the service delivery division of a leading global telecommunications company. The first phase of the research focused on the analysis of the current situation of GFBE. It identified inefficient business processes as the subject for developing and implementing a BP model that implies V\&S methods. After implementing GFBE's BP model, the results suggest that control measures had to be put in place to determine if the model was meeting its purpose of improving GFBE's processes. These control measures include adding, rearranging, and eliminating processes, served as corrective actions (Ariyachandra and Frolick, 2008) to reduce lost lead-time in service delivery. Therefore, the application of such control measures is a good litmus test to determine the process model's practicality and effectiveness. The V\&S methods were 
applied and monitored in the second phase of the research to test their performance impact. The findings suggest that visualising and standardising the BP model helped improve communication among the organisation's relevant stakeholders. Furthermore, it offers a blueprint for decisionmaking and enables further improvement in the long run. The developed processes helped identify and manage the complex interrelationship of BPs and improve organisational performance because they work together to facilitate the integration and alignment of their different BPs, as seen in the results presented in section 4 .

The third phase of the research focused on the impact the revised BP model had on organisational performance. Implementing the BP model and the V\&S methods influenced organisational performance in that it achieved a time reduction in service delivery. The use of the dual methods enabled GFBE to understand how to align the different BPs involved in service delivery to identify and manage their interrelationship and implement a PIIs, resulting in improved organisational performance. The fourth phase revealed the importance of continuous improvement and agile practices to react rapidly to changes in a given context. Constant evaluation and redesign are required to undertake the long-time changes and reach the necessary impact. The suggested implementation process is depicted in Figure 11:

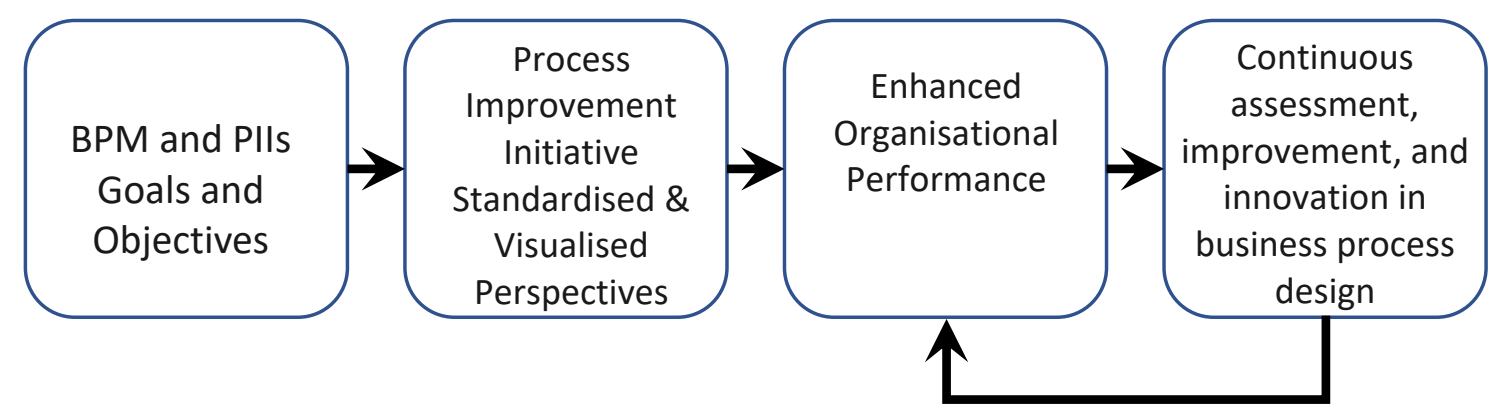

Figure 11: Research Model

The research model in Figure 11 deploys the BP model from the view of the process improvement initiatives (PIIs) concept to explain how to enhance the management of processes through a series of process changes and improvements. GFBE's stakeholders perceived the importance of the combined use of V\&S methods. It is a vital prerequisite for successfully implementing PIIs and enhancing organisational performance. It also helps answer our central research question: how and 
when using the V\&S methods can lead to successful process improvement and organisational performance. As shown in Table II below, using both methods are crucial. If standardisation was incorporated in the BP model without visualisation, GFBE would have achieved only efficiencies in product procurement and the planning of product expenditure and little improvement in the supply chain and process management. If only the visualisation method were incorporated, GFBE would benefit only by monitoring and understanding the interrelated and complex business activities and resolving stakeholders' different perceptions.

Table II: The Benefits of Dual Methods

\begin{tabular}{|l|c|c|}
\hline Process & Standardisation & Visualisation \\
\hline Planning of product expenditure & $\mathrm{X}$ & \\
\hline $\begin{array}{l}\text { Cutting cost and time of procurement and } \\
\text { delivery from suppliers to customers }\end{array}$ & $\mathrm{X}$ & \\
\hline $\begin{array}{l}\text { Improving workflow management } \\
\text { Monitoring the interrelated and complex } \\
\text { flow of business activities }\end{array}$ & $\mathrm{X}$ \\
\hline $\begin{array}{l}\text { Understanding the interrelated and complex } \\
\text { flow of business activities }\end{array}$ & $\mathrm{X}$ \\
\hline $\begin{array}{l}\text { Resolving ambiguity arising from } \\
\text { stakeholders having different time } \\
\text { expectations in resolving requests }\end{array}$ & $\mathrm{X}$ & $\mathrm{X}$ \\
\hline $\begin{array}{l}\text { Enhancing control and traceability } \\
\text { Quick identification of issues which require }\end{array}$ & $\mathrm{X}$ & \\
\hline
\end{tabular}

Our results complement previous studies (e.g., Kolb and Reichert, 2013; Vergadis et al., 2008; Villalba-Diez, and Ordieres-Meré, 2015), which highlight that organisations prefer to deal with BPs that are clear and logically structured, to reduce ambiguity when managing BPs. Similarly, our research findings are consistent with Tang et al. (2013, p. 657), who argue that "process 
management and measurement influence organisational innovation performance through customer integration and employee innovativeness". At the same time, however, they also differ from Tang et al.'s (2013) findings. Taking the 'process view', i.e., adopting a visualisation method to implement PIIs, did not significantly affect organisational innovation performance. The study adopted a visualisation method to implement PIIs, allowed GFBE to simplify, remodel, and develop its BP in a way that effectively meets customer expectations and consequently enables process innovation and enhances organisational performance. We acknowledge that continuous organisational learning is critical to redesign and redeploy the gained experience in other valuedriven business processes in different organisation divisions.

\section{Conclusion}

The purpose of this research was to investigate the process improvement initiative (PII), focusing on how the visualisation and standardisation (V\&S) methods can improve business processes (BPs) and organisational performance. The literature suggests that the design and implementation of an organisation's BPs must crucially consider the V\&S methods on business process management (BPM). Nonetheless, the literature has not adequately explored each of these methods' precise impact on improving organisations' processes and performance. Researchers in this field have also called for value-driven studies of BPM, which place a sharper focus on the desired organisational outcomes instead of just BPM methods (e.g., Klun and Trkman, 2018; vom Brocke and Rosemann, 2015). This research responds to this call by taking the V\&S methods to examine their contribution to PIIs. We implemented the model in customer requests and ICT service delivery processes, and the benefit was evidenced by reducing lost lead-time in the organisation's processes. Consequently, improving the organisation's performance and leading to improvement and innovation in BP design. We highlight the study's contributions to the body of knowledge as follows:

- It shows how the implementation of a BP model as part of PII proved to be useful for both managers and employees; this stands in contrast to previous research, which suggests that taking the process orientation to BPM is insufficient to improve innovation organisational performance (Tang et al., 2013). While our findings show that standardisation can help process innovation when it is adopted in the early stages. Simultaneously, visualisation is 
always required for evaluation and shift thinking toward more innovative process design and execution.

- The results show that all the processes in the entire service delivery flow need to be V\&S to promote a smooth way of working and avoid ambiguity regarding employees' roles and responsibilities. Partial V\&S processes might not bring the required results; instead, holistic end-to-end processes must be considered. Engaging users and communicating effectively to all stakeholders is vital for the measurement of organisation performance regularly. Such measurement gives a full picture of where the organisation stands and areas that require more attention and action for the organisation's greater success.

- When the visual and standardised process model is internalised, and full potential efficiency is realised. Managers with caution might break part of the standardised project management to enable process innovation. Visualisation can aid the evaluation and assessment of the innovative improvement before moving into operation. Moreover, adopting the V\&S methods thus offers a better chance of improving processes and achieving better organisational performance than taking only one of these methods. These contributions are significant because they can suggest strategies for organisations to identify underlying problems in the entire flow of processes and then identify, design, and confirm value-added activities for BPM's successful deployment.

We acknowledge some limitations in the study as follows:

- Although the paper considers the flexibility in the standardisation of BPs as it gives scope for innovation and creativity on the part of the process, it can be asked whether flexibility is possible without breaking the standardised way of working and how much flexibility is appropriate. Further research can take the research model and test it within a different context and with various business scenarios or different BPs to find the optimum balance between standardisation and flexibility. Future research can also hypothesise the BPM model and test its statistical generalisability by conducting a survey.

- Different V\&S methods might affect the overall performance in different ways. While this study used the BP modelling standard, different standards should be evaluated regarding their business performance impact. A future study on empirical applications of different visualisation standards may be essential to determine their organisational performance effects. 


\section{References}

Alles, M., Brennan, G., Kogan, A. and Vasarhelyi, M. A. (2006), "Continuous monitoring of business process controls: A pilot implementation of a continuous auditing system at Siemens", International Journal of Accounting Information Systems, Vol. 7, No. 2, pp. 137161.

Anand, G., Ward, P. T., Tatikonda, M. V. and Schilling, D. A. (2009), "Dynamic capabilities through continuous improvement infrastructure", Journal of Operations Management, Vol. 27, No. 6, pp. 444-461.

Anttila, J. and Jussila, K. (2013), "An advanced insight into managing business processes in practice", Total Quality Management Business Excellence, Vol. 24 No. 7-8, pp. 918-932.

Ariyachandra, T. R. and Frolick, M. N. (2008), "Critical Success Factors in Business Performance Management - Striving for Success", Information System Management, Vol. 25 No. 2, pp. 113120.

Barley, S. R. (1990), "Images of imaging: notes on doing longitudinal field work", Organization Science, Vol. 1, No. 3, pp. 220- 247.

Bobrik, R., Reichert, M. and Bauer, T. (2007), "View-based process visualization", in International Conference on Business Process Management 2007 proceedings of the international conference in Springer Berlin Heidelberg, 2007, pp. 88-95.

Boudreau, M.-C., \& Robey, D. (1996). Coping with contradictions in business process reengineering, Information Technology \& People, Vol. 9, No. 4, pp. 40-57.

Damij, N. (2007), "Business process modelling using diagrammatic and tabular techniques", Business Process Management Journal.

Dijkman, R., Lammers, S.V. and de Jong, A. (2016), "Properties that influence business process management maturity and its effect on organizational performance", Information Systems Frontiers, Vol. 18, No. 4, pp. 717-734.

Eikebrokk, T. R., Iden, J. Olsen, D. H. and Opdahl, A. L. (2011), "Understanding the determinants of business process modelling in organisations", Business Process Management Journal, Vol. 17 No. 4, pp. 639-662.

Fayoumi, A., \& Loucopoulos, P. (2016), "Conceptual modeling for the design of intelligent and emergent information systems", Expert Systems with Applications, Vol. 59, pp. 174-194. 
Fenton, E. M. (2007), "Visualising strategic change: the role and impact of process maps as boundary objects in reorganisation", European Management Journal, Vol. 25 No. 2, pp. 10417.

Figl, K. (2017), "Comprehension of procedural visual business process models", Business \& Information Systems Engineering, Vol. 59, No. 1, pp. 41-67.

Graves, T. (2014), "Enterprise as Story, Enterprise as System, Systems Thinking in Enterprise Architecture", In J. G. a. A. Jensen-Waud (Ed.), Beyond Alignment: Systems Thinking in Enterprise Architecture: College Publications.

Klun, M. and Trkman, P. (2018), "Business process management-at the crossroads", Business Process Management Journal.

Kolb, J., and Reichert, M. (2013). "Data flow abstractions and adaptations through updatable process views". In Proceedings of the 28th annual ACM symposium on applied computing (pp. 1447-1453).

Leontjeva, A., Conforti, R., Di Francescomarino, C., Dumas, M., \& Maggi, F. M. (2016, September). Complex symbolic sequence encodings for predictive monitoring of business processes. In International Conference on Business Process Management (pp. 297-313). Springer, Cham.

Lok, P., Hung, R.Y., Walsh, P., Wang, P. and Crawford, J. (2005), "An integrative framework for measuring the extent to which organizational variables influence the success of process improvement programmes", Journal of Management Studies, Vol. 42 No. 7, pp. 1357-1381.

Marcinkowski, B., \& Gawin, B. (2019), "A study on the adaptive approach to technology-driven enhancement of multi-scenario business processes", Information Technology \& People.

Melã o, N. and Pidd, M. (2001), "A conceptual framework for understanding business processes and business process modelling", Information Systems Journal, Vol. 10 No. 2, pp. 105-129.

Mustonen-Ollila, E. and Lyytinen, K. (2003), "Why organizations adopt information system process innovations: a longitudinal study using Diffusion of Innovation theory", Information Systems Journal, Vol. 13, No. 3, pp. 275-297.

Münstermann, B., Eckhardt, A. and Weitzel, T. (2010), "The performance impact of business process standardization", Business Process Management Journal, Vol. 16 No. 1, pp. 29-56. 
Nadarajah, D., Syed A. Kadir, S. L., S., A. (2016), "Measuring Business Process Management using business process orientation and process improvement initiatives", Business Process Management Journal, Vol. 22 No. 6, pp. 1069-1078.

Pettigrew, A. M. (1990), "Longitudinal field research on change: theory and practice", Organization Science, Vol. 1, No. 3, pp. 267-292.

Phelps, R. (2006), "Process standards: Pursuing best practices", Controlling Engineering, Vol. 53, pp. 69-74.

Rinderle, S. B., Bobrik, R., Reichert, M. and Bauer, T. (2006), "Business process visualizationuse cases, challenges, solutions, in International Conference on Enterprise Information Systems 2006 proceedings of the international conference in Paphos - Cyprus, 2006, Springer, pp. 204211.

Rondini, A., Pezzotta, G., Cavalieri, S., Ouertani, M. Z., and Pirola, F. (2018). "Standardizing delivery processes to support service transformation: A case of a multinational manufacturing firm". Computers in Industry, Vol. 100, pp. 115-128.

Romero, H. L., Dijkman, R. M., Grefen, P. W. and van Weele, A. J. (2015), "Factors that Determine the Extent of Business Process Standardization and the Subsequent Effect on Business Performance", Business \& Information Systems Engineering, Vol. 57 No. 4, pp. 261270.

Sánchez-Rodríguez, C., Hemsworth, D., Martínez-Lorente, Á. R. and Clavel, J. G. (2006), "An empirical study on the impact of standardization of materials and purchasing procedures on purchasing and business performance", Supply Chain Management: An International Journal, Vol. 11 No. 1, pp. 56-64.

Skrinjar, R. and Trkman, P. (2013), "Increasing process orientation with business process management: critical practices", International Journal of Information Management, Vol. 33 No. 1, pp. 48-60.

Stentoft Arlbjørn, J. (2011), "Process optimization with simple means: The power of visualization", Industrial and Commercial Training, Vol. 43 No. 3, pp. 151-159.

Tang, J., Pee, L.G. and Iijima, J. (2013), "Investigating the effects of business process orientation on organizational innovation performance", Information \& Management, Vol. 50 No. 8, pp. 650-660. 
Van Looy, A., Poels, G. and Snoeck, M. (2017), "Evaluating business process maturity models", Journal of the Association for Information Systems, Vol. 18, No. 6, pp. 1.

Veit, D., Clemons, E., Benlian, A., Buxmann, P., Hess, T., Kundisch, D., Leimeister, J.M., Loos, P. and Spann, M. (2014), "Business models - an information systems research agenda", Business \& Information Systems Engineering, Vol. 6 No. 1, pp. 45-53.

Vergidis, K., Turner, C. J. and Tiwari, A. (2008), "Business process perspectives: Theoretical developments vs. real-world practice", International Journal of Production Economics, Vol. 114 No. 1, pp. 91-104.

Villalba-Diez, J., and Ordieres-Meré, J. (2015). "Improving manufacturing performance by standardization of interprocess communication", IEEE Transactions on Engineering Management, Vol. 62 No 3, pp. 351-360.

vom Brocke, J., Zelt, S., and Schmiedel, T. (2016). "On the role of context in business process management", International Journal of Information Management, Vol. 36 No. 3, pp. 486-495.

vom Brocke, J., and Rosemann, M. (2015). Handbook on business process management: introduction, methods and information systems. Berlin: Springer.

Walsham, G. (2006), "Doing Interpretive Research", European Journal of Information Systems, Vol. 15 No. 3, pp. 320-330.

Weber, R. (2004), "The Rhetoric of Positivism versus Interpretivism", MIS Quarterly, Vol. 28 No. 1, pp. 3-1

Wong, W. P. (2013), "Business-process management: a proposed framework for future research", Total Quality Management Business Excellence, Vol. 24 No. 5-6, pp. 719-732.

Wüllenweber, K., Beimborn, D., Weitzel, T. and König, W. (2008), "The impact of process standardization on business process outsourcing success", Information Systems Frontiers, Vol. 10 No. 2, pp. 211-224.

Yin, R. K. (2009), Case study research: Design and methods, 4th ed., Sage Publications, Thousand Oaks, CA.

Zairi, M. (1997), "Business process management: a boundaryless approach to modern competitiveness", Business Process Management Journal, Vol. 3 No. 1, pp. 64-80. 